\title{
THEORETICAL ASPECTS OF THE CONCEPT OF COMMUNITY IN THE CONTEXT OF SOCIAL SCIENCES
}

\author{
Evija Piebalga1, Anda Zvaigzne ${ }^{2}$ \\ ${ }^{1}$ Mg.soc.sc., senior project manager, Rezekne Business Incubator, Rezekne, Latvia, \\ e-mail: evija.piebalga@liaa.gov.lv \\ ${ }^{2}$ Dr.oec., associate professor, leading researcher, Rezekne Academy of Technologies, \\ Rezekne, Latvia, e-mail: anda.zvaigzne@rta.lv
}

\begin{abstract}
Various world-class research investigations increasingly focus on matters pertaining to the role of local communities.

The research aimed to examine the theoretical aspects of the concept of community in the context of social sciences. The research results revealed that community studies was a relatively new field for academics in Latvia, which became relevant after common European Union priorities in community issues were defined. An essential feature of a community is common identity, a common sense of belonging to the locality, human relationships, the environment, culture and values. Most frequently, according to a survey of local residents, a community the respondents felt a sense of belongingness to was a territorial one.

The research employed the following methods: monographic, descriptive, graphic, analysis, synthesis as well as a sociological method - questionnaire surveying.
\end{abstract}

Keywords: local community, kinds of communities, population, organisations. JEL code: Z10, D83.

\section{Introduction}

Various world-class research investigations increasingly focus on matters pertaining to strategic regional development, resource use and sustainability as well as the role of local communities in it. Extensive research on communities is done in the United States of America, the United Kingdom, Australia and Canada. Most of the research investigations are based on a conviction that regional and national sustainability could be achieved only in case problems are tackled and decisions are made by engaging all stakeholders: decision makers, community-level organisations, local communities and local residents. Community studies have become important both in research and in strategic regional and national development planning relatively recently, which is confirmed by a number of national-level strategic policy documents stressing the role of local communities in particular in regional and national socio-economic and overall development. The National Development Plan 2014-2020 (NDP, 2012), which is the hierarchically highest medium-term policy document, and the Sustainable Development Strategy of Latvia until 2030 (SDSL, 2030), which states that individuals, their talents, knowledge and creativity as well as ability to cooperate and collectively do what is impossible to do individually are an important kind of capital and a growth resource, are

This is an open access article under the Creative Commons Attribution 4.0 International License. 
referred to as the most important policy documents. Cooperation and participation are among the key strategic principles for sustainable national development (Škin, kis et al., 2015).

It is important that to date in Latvia, socio-economic development has been assessed by applying an approach that uses a generalised territorial development index not giving an in-depth insight into specific development trends. The measurements focusing on a regional territory and its human capital and local community capacity that are comparable regionally throughout Latvia have not been carried out to date, although public capacity in particular is also viewed as making current or expected effects on development processes in the particular territory. As the population decreases, it is important to maintain the endowment and productivity of national human capital and, in addition, to take into account community capacity aspects such as participation in developing governance and the educational and cultural space, as only the activity of the individual or some societal groups and the opportunities given to them are the key characteristics of potential for territorial development.

The research aim is to examine the theoretical aspects of the concept of community in the context of social sciences.

To achieve the aim, the following specific research tasks are set:

1. To examine the concept and kinds of community;

2. To identify the public's understandings of the idea of community in a regional context.

Hypothesis: the public comprehends the idea of community and have a sense of belonging to some certain community.

The research employed the following methods: monographic, descriptive, graphic, analysis, synthesis as well as a sociological method questionnaire surveying.

The questionnaire survey was conducted on a social media platform Facebook -, questioning the residents of Rezekne city as well as the municipalities of Rezekne, Vilani, Ludza, Balvi, Zilupe, Baltinava, Karsava, Rugaji, Cibla, Zilupe and Vilaka. The survey was carried out in the period 1025 March 2019, and totally 152 questionnaires were valid for processing.

The present research was done based on relevant research papers by foreign and national scientists as well as industry specialists and other sources of information as well as on the survey data.

\section{Research results and discussion}

In modern societies, individuals are mainly guided by individual choices, yet there are events and processes that are beyond the individuals' control; therefore, communities are still an important element of social 
structure that acts in the social environment as an intermediary among the individual, small societal groups and the broader public (Blackshaw, 2010). It is confirmed by the research done by French sociologist and philosopher Jean-François Lyotard on postmodern communities - "in postmodern societies too, any of us is involved in some social relationships since birth. The individual's life occurs in communities that represent certain social network structures. The community represents certain values, lifestyles, conviction and identity" (Lyotard, 1984).

Communities can emerge owing to various processes and have various goals that are common for a certain group of individuals who share common beliefs, interests and relationships, live in the same conditions and territory and have the same ethnicity and occupation (Peterman, 2000), as the communities do not exist in a vacuum - they occupy certain geographical locations (Buttimer, 1976). R.J.Chaskin (Chaskin, 1997), a researcher of territorial communities and community initiatives, points out that communities can emerge as a result of various certain circumstances, yet he views the common things through the combination prism. He believes that any kind of community involves combinations. The combination networks could be and could not be territory-based. For example, ethnic communities are united by culture, religious ones - by beliefs and professional ones - by interests and conditions. At the same time, any community occupies a certain location, yet the location is not only geographical. A community is a spatial unit involving certain combinations - social (e.g. friendship), cultural (e.g. traditions), functional (e.g. consumption), conditional (e.g. lifestyle). At the same time, "territory" and "place" represent a significant basis for any community - the community has a certain location, yet the same territory is not a significant constituent element for any community (Zobena et al., 2015). For this reason in research, the concept of community is usually attributed both to the territory where the community members reside and where they communicate and socially interact and to the group of individuals sharing the same interests but not the same neighbourhood. Quite often, both understandings overlap. The unifying factor of a territorial community is the shared territory and a certain attitude to it, but overall, the geographical idea of communities is associated with certain common characteristics, e.g. interests and identity that unite the individuals (Wromen, 2015). According to a definition, a community itself is a social system that satisfies the needs of its members (Flora et al., 2012) and only formal parameters - territory, social strata or status, ethnicity or gender - do not constitute the community. A community could not be characterised only by seemingly determinant criteria. An essential feature of a community is common identity, a common sense of belonging to the locality, human relationships, the environment, culture and values. A community is a socially constructed concept. 
Community member relationships are based on common history, values and social norms, status, role patterns and mutual expectations. The elements create a sense of identity that is psychologically and socially important (Brager et al., 1987). Basically, six kinds of community are distinguished:

- interest communities, in which the members are united by common interests, the desire for a particular thing beyond which the members are not interested in one another (e.g. Playstation StarWars);

- $\quad$ practice communities, in which the members are united by a common activity or a particular field, seek expert opinions and act as a knowledge and expertise resource in the particular field (e.g. a doctor association, IT specialists);

- action communities, in which the members are united by a common goal, report on progress and development, share their successful experience and contribute to the progress of smaller groups (e.g. environmental protection clubs);

- conditional communities, in which the members are united by common challenges or situations that have not emerged because of their behaviours, focus on giving mutual support and strengthening mutual relationships (e.g. war veterans);

- territorial communities, in which the members are united by a common territory and location, place a focus on local-level events and local residents and motivate the mutual exchange of information and experience);

- hybrid communities represent a combination of the mentioned kinds of community: territorial/practice, territorial/interest, territorial/conditional, practice/action, action/interest, action/conditional, practice/interest, practice/conditional, action/interest, action/conditional, practice/conditional and interest/practice (FeverBee (community consultancy), 2010).

In 1955, American sociologist George Hillary published a paper entitled "Definitions of Community: Areas of Agreement", in which he provided at least 94 definitions of community that had only one common element: all the definitions refereed to individuals. Sociologists Colin Bell and Howard Newby summarised the definitions and came to a conclusion that three elements could be clearly identified with regard to communities: social interaction, common relationships and a common territory. This also confirms the idea of community, generated by sociologists, in two ways. It, first, is a kind of relationships, a sense of identity and the unity of a group of individuals, which, second, is undoubtedly consistent with some ideological arguments in classical sociology if simply extending the concept of geographical territory (Bell et al., 1971). 
Discussions on the role of communities in the social structure of a society increasingly raise questions on values and social norms. Values and wishes together create a disposition that is broader than the concept of intent. A disposition is characterised by action-oriented consciousness that does not exclude emotional attitude. Dispositions emerge in education, the social environment and everyday experience (Lasmane, 2002).

There is no denying that communities can offer support, guidance and a sense of belonging, yet the membership of a community does not need to be mandatory or restrictive. A community should be an environment where different views, beliefs, identities and priorities could be discussed, and there has to be a strategy that promotes the "community" in society as the desired goal of public participation and engagement (Kahne et al., 1996). Various desires and needs bring individuals together whose relationships either arise from their own to other needs and desires or ignore, exclude and reject them (Lasmane, 2002). Since democratic societies respect individual and group differences, communities also need to admit and support diversity through contributing to conversation techniques and avoiding disagreements. Nowadays, a community has changed from an end in itself to an instrument for solving certain social problems.

To identify the public's understandings of the idea of community in a regional context, the authors designed a questionnaire "Do You Know what a Community is?", which was distributed on the Facebook platform, requesting the residents of Rezekne city as well as the municipalities of Rezekne, Vilani, Ludza, Balvi, Zilupe, Baltinava, Karsava, Rugaji, Cibla, Zilupe and Vilaka to fill it in. The survey was carried out in the period 10-25 March 2019 , and totally 152 questionnaires were received back. To get insight into the social profile of the respondents, the questionnaire included questions on their genders, ages, occupations and residence places. Most of the respondents were women - 81.6\%, while men were $18.4 \%$. The most represented age group was $25-40$ years, $56.6 \%$, followed by the age groups of $40-60$ with $21.1 \%$ and $16-25$ with $20.45 \%$, while the respondents aged less than 16 constituted only $2 \%$. Most of the respondents had their main jobs in the private sector $-38.2 \%, 37.5 \%$ worked in the public sector or at municipal institutions, $15.1 \%$ had university student status, $5.9 \%$ were schoolchildren, 5.3\% indicated they were unemployed, while the answer option "other" included the following answers: a mother, an artist, an employer, an employee working abroad etc.

In a multiple choice question with several answers possible, the survey offered a number of associative assertions, and the respondents could choose several ones being most adequate to their understandings of the idea of community. According to the survey, the dominant opinion was that a community was an interest group $-50 \%$, followed by a community as a 
group of individuals living separately from the rest of the society, with their own life philosophy and rules $-45.5 \%$, a community as a creative, socially active group $-43.4 \%$ and a diaspora community $-42.1 \%$. It is essential that $35.5 \%$ of the respondents associated the idea of community with regional organisations dealing with the social and economic development of the region. This indicates that even though this opinion was not dominant, a relatively larger number of the respondents associated the idea of community with regional organisations than with virtual communities and minority groups (see Table 1 ).

Table 1 Respondents' associations with the idea of community (authors' compilation based on the survey data)

\begin{tabular}{|l|c|}
\hline Kind of associations with the idea of community & $\begin{array}{c}\text { Respondent } \\
\text { answers, \% }\end{array}$ \\
\hline $\begin{array}{l}\text { A group of individuals living separately from the rest of the society, } \\
\text { with their own life philosophy and rules }\end{array}$ & 45.4 \\
\hline $\begin{array}{l}\text { Creative, socially active groups (e.g. dance bands, music bands, } \\
\text { amateur theatres etc.) }\end{array}$ & 43.4 \\
\hline $\begin{array}{l}\text { Interest groups (e.g. book clubs, entrepreneur organisations, } \\
\text { healthy lifestyle, hobbies etc.) }\end{array}$ & 27 \\
\hline $\begin{array}{l}\text { Minority groups (e.g. sexual minorities, ethnic groups, migrants } \\
\text { etc.) }\end{array}$ & 25 \\
\hline $\begin{array}{l}\text { Virtual communities (e.g. geocaching players, Star Wars, virtual } \\
\text { game fan communities etc.) }\end{array}$ & 38.8 \\
\hline Religious communities (e.g. Roman Catholics, Baptists etc.) & 42.1 \\
\hline $\begin{array}{l}\text { Diaspora communities (e.g. Latvian diasporas in Brazil, the United } \\
\text { Kingdom, the USA etc.) }\end{array}$ & 35.5 \\
\hline $\begin{array}{l}\text { Religious organisation communities dealing with the social and } \\
\text { economic development of the region (e.g. the Leader programme, } \\
\text { business incubators, NGOs etc.) }\end{array}$ & 25.7 \\
\hline Territorial communities, belongingness to the place where I live & 2.8 \\
\hline $\begin{array}{l}\text { Other: all the above, ecovillages, resident communities as such, } \\
\text { communities beyond political context }\end{array}$ & 27 \\
\hline
\end{tabular}

The questionnaire included a question on whether the respondent felt him/herself belonging to a community and what community it was. Totally, 124 respondents out of 152 answered this question, of which 7 indicated they did not feel themselves belonging to any community. The answers were grouped by the explanations for the concept of community given in Table 1 that shows answer percentages, not a percentage breakdown of the answers. The most respondents - 23 - felt themselves belonging to a community as an interest group, and most often it was a student community, an alumni 
community, a colleague community and an entrepreneur community in the region. The second community referred to most often was a territorial community with 17 answers, and the answers indicating belongingness to Latgale - the region where Latgalians lived - dominated. Of the total respondents, 37 indicated they felt themselves belonging to a community, yet they either did not specify it or their kind of community did not match any one given in Table 1; they indicated various other kinds of community - a diabetes community, a community of volunteers, the Latvian mental strength community, family etc. It has to be added that 17 respondents answered they belonged to regional organisation communities, most often referring to their belonging to the Latvian Investment and Development Agency's Rezekne Business Incubator community.

Most of the respondents - 84\% - associated the idea of community with an open group of individuals. Answering a question on discussions on the idea of community in the public arena, $68 \%$ respondents indicated the idea was sufficiently or well discussed and explained, while the rest of them believed it was not sufficiently done in the public arena.

\section{Conclusions and proposals}

1. Community studies is a relatively new field for academics in Latvia, which became relevant after common European Union priorities in community issues were defined. An essential feature of a community is common identity, a common sense of belonging to the locality, human relationships, the environment, culture and values.

2. The hypothesis put forward proved to be true only partly, as $35.5 \%$ of the respondents indicated they associated the idea of community with regional organisations dealing with the social and economic development of the region. This indicates that even though this opinion was not dominant, a relatively larger number of the respondents associated the idea of community with regional organisations than with virtual communities and minority groups.

3. The survey revealed that a community the respondents felt a sense of belongingness to was a territorial one.

4. The emergence of a community involves many challenges at both the regional and national levels. There is a lack of strategic, political initiatives for promoting the development of communities; therefore, local and regional organisations have to contribute to strengthening a sense of belongingness to a community in local residents in particular. 


\section{References}

1. Bell, C., Howard Newby, H. (1971). Community studies: an introduction to the sociology of the local community. London: Allen and Unwin, $73 \mathrm{p}$.

2. Blackshaw, T. (2010). Key Concepts in Community Studies. SAGE Publications Ltd, $17 \mathrm{p}$.

3. Brager, G., Specht, H., Torczyner, J.L. (1987). Community Organizing. Columbia University Press, 78 p.

4. Buttimer, A., (1976). Grasping the dynamism of lifeworld. Annals of the Association of American Geographers. Vol. 66, pp. 277-292.

5. Chaskin, R.J. (1997). Perspectives on Neighborhood and Community: A Review of the Literature. Social Service Review, 71(4), pp. 521-547.

6. FeverBee (community consultancy) (2010). Different Types Of Communities. Retrieved from https://www.feverbee.com/different-types-of communities

7. Flora, C.B., Flora, J.L. (2012). Rural Communities: Legacy and Change. Westview Press, $7 \mathrm{p}$.

8. Kahne, J., Westheimer, J., King, S.H. (1996). Visions of Community and Education in a Diverse Society. Retrieved from https://www.hepg.org/her-home/issues/harvardeducational-review-volume-66-issue-4/herarticle/_248

9. Lasmane, S. (2002). Communication Ethics. Riga: University of Latvia, 133 p.

10. Lyotard, J.F. (1984). The Postmodern condition: A report on knowledge. Minneapolis: University of Minnesota Press, $11 \mathrm{p}$.

11. National Development Plan (NDP) 2014-2020 (2012). Retrieved from http://polsis.mk.gov.lv/documents/4247

12. Peterman, W. (2000). Neighborhood Planning and Community - Based Development: The Potential and Limits of Grassroots Action. SAGE Publications, Inc. 208 p.

13. Šķin,ķis, P., Villa, I., Cimdiņš, R., Ušacka, M. (2015). Territorial Human capital and Community Capacity Index. Notebook 4 - an annex for the book New Approaches to Measuring Social Development. Riga: University of Latvia, 7 p.

14. Sustainable Development Strategy of Latvia (SDSL) until 2030 (Latvija2030). Retrieved from http://www.latvija2030.lv

15. Wromen, A. (2015). City and community. American Sociological Association. 47 p.

16. Zobena, A., Ijabs, I. (2015). New Approaches to Measuring Social Development: Individual, Territories, Municipalities, Riga: University of Latvia, $42 \mathrm{p}$. 